The relative effects of deprivation of the latent and manifest benefits of employment on the wellbeing of unemployed people

Authors: $\quad$ Peter A. Creed, Griffith University - Gold Coast

Sean R. Macintyre, Griffith University - Gold Coast

Contact: $\quad$ Dr Peter Creed

School of Applied Psychology

Griffith University

Gold Coast Campus

PMB 50, GCMC 9726

Gold Coast

Email: p.creed@mailbox.gu.edu.au 


\title{
The relative effects of deprivation of the latent and manifest benefits \\ of employment on the wellbeing of unemployed people
}

\begin{abstract}
This study investigated the relative contributions of the individual latent and manifest benefits of employment to wellbeing in a sample of 248 unemployed people. Participants completed measures of wellbeing and the latent (time structure, activity, status, collective purpose, and social contact) and manifest benefits of employment (financial strain). Significant associations were found between the latent benefits and wellbeing, and between the manifest benefits and wellbeing. Both latent and manifest benefits contributed significantly to the prediction of wellbeing, with the manifest benefit accounting for the largest proportion. While all latent benefits did contribute significantly, individually status emerged as the most important contributor, followed by time structure and collective purpose. Results are discussed in the context of Jahoda's (1982) Latent Deprivation Model and Fryer's (1986) Agency Restriction Model.
\end{abstract}


Research examining the impact of unemployment on the general functioning of unemployed people has been conducted across many countries and now spans more than 60 years from the Great Depression of the 1930's to the present (for a recent review, see Winefield, 1995). This research has demonstrated that unemployment has a deleterious effect on the psychological wellbeing of the individuals involved. For example, when unemployed are contrasted with employed people, the unemployed report higher levels of psychological distress (Henwood \& Miles, 1987) and depression (Feather \& O'Brien, 1986), and report lower levels of self-esteem (Muller, Hicks \& Winocur, 1993). Further, where longitudinal studies have been conducted, they have demonstrated that these negative effects are largely the result of people becoming unemployed and not the result of individuals with fewer personal skills and poorer mental health “drifting" into joblessness (for recent review see Murphy \& Athanasou, 1999).

Two specific unemployment theories have been proposed to account for the deterioration in wellbeing observed when people are exposed to unemployment. These two theories are the Latent Deprivation Model proposed by Jahoda (1982), and the Agency Restriction Model proposed by Fryer (1986). These two theories have dominated the research and applied efforts in the area of unemployment and mental health (Haworth, 1997).

Firstly, Jahoda argued that paid work provides both manifest (associated with income) and latent benefits (associated with meeting psychological needs). People primarily engage in paid work to attain manifest benefits, but while employed profit from the five latent benefits of time structure, social contact, common goals, status and activity. Deprivation of employment leads to deprivation in both manifest and latent benefits, but it is the loss of the latent benefits that impacts negatively on psychological wellbeing. Jahoda (1984) argued that individuals, “... have deep seated needs for structuring their time use and perspective, for enlarging their social horizon, for participating in collective enterprises where they can feel useful, for knowing they have a recognized place in society, and for being active..." (p. 298). 
Evidence in support of Jahoda's account has come from researchers who have used scales developed specifically to measure the latent benefits. Miles (1983) demonstrated that unemployed adults varied in their levels of access to the latent benefits. Miles and Howard (1984) and Evans and Haworth (1991) identified differences on the latent benefits between employed and unemployed youth. Creed and Machin (2001) demonstrated that unemployed individuals had less access to some of the latent benefits than those underemployed, and that those with no recent paid work had less access than those with recent or current paid work. Miles, Miles and Howard, and Evans and Haworth all reported significant associations between the latent benefits and wellbeing. By and large, these studies have shown that unemployed people do differ from employed people on access to the combined latent benefits, and that those with better access generally have better mental health.

Other researchers have examined the latent benefits of employment separately and reported their effect on psychological wellbeing. Jahoda (1982) argued that the most important of the latent benefits was time structure, and that the loss of this benefit was "experienced as a heavy psychological burden" (p. 23). A number of researchers have reported that unemployed people have less structured and purposeful time use than the employed (Jackson, 1999; Wanberg, Griffiths, \& Gavin, 1997). Further, there has been consistent evidence that time structure is related to psychological wellbeing. Hepworth (1980) found that the best predictor of mental health was whether individuals felt their time was occupied. Other authors have linked lower levels of structured and purposeful time use to lower levels of self-esteem, more depression and higher levels of psychological distress (Bond \& Feather, 1988; Evans \& Haworth, 1991; Rowley \& Feather, 1987; Ullah, 1990). Winefield, Tiggemann and Winefield (1992), in a large-scale longitudinal youth study concluded that time structure played a buffering role in mediating the negative effects of unemployment. 
For activity, unemployed people have been found to have lower levels of activity than the general population (Underlid, 1996). A number of studies have also found a relationship between activity level and wellbeing in the unemployed. Haworth and Ducker (1991) found unemployed people who spent more time in competence serving activities such as household chores, socialising and active leisure and less time spent idling and in passive leisure to have better psychological wellbeing. Winefield, Tiggemann and Winefield (1992) found that structured or socially gregarious activity as distinct from unstructured or aimless activity was better for psychological wellbeing in unemployed youth. Evans and Haworth (1991) divided their sample into two groups based on their level of activity. Those with higher levels of activity had more access to the other latent benefits than those in the lower activity group. When the authors controlled for the effects of activity, the relationship between time structure and collective purpose and wellbeing disappeared. The authors believed that activity played an important mediating influence in gaining access to the other latent benefits of employment for the unemployed. Evans (1986; cited in Evans \& Banks, 1992) also argued that activity might be superordinate in terms of its contribution to wellbeing.

Social contact has been shown to have positive effects on psychological wellbeing (Haworth \& Ducker, 1991; Henwood \& Miles, 1987) and depression (Bolton \& Oatley, 1987). Kilpatrick and Trew (1985) found that an unemployed sample with high levels of social contact had superior wellbeing to those unemployed who had few social contacts. Hammer (1993) found that social support from a close social network of family and friends moderated some of the negative effects of unemployment on wellbeing. This author also found that social isolation was linked to low self-esteem. Unemployed people have also been found to be involved in fewer social activities than those not unemployed (Underlid, 1996), and to have less social support from close relations and authority figures when compared with an employed group (Jackson, 1999). 
Less empirical work has examined the relationship between collective purpose and wellbeing. Jahoda (1982) argued that outside of the nuclear family it was employment that provided a stage for people to feel a part of society, and that the loss of this benefit was related to lower wellbeing. For unemployed people, Haworth and Patterson (1995) found that collective purpose was significantly related to wellbeing if gained through work or leisure activities. Further, feelings of having a collective purpose or common goals have been found to be associated with wellbeing in unemployed samples (Evans \& Haworth, 1991; Haworth \& Ducker, 1991).

Jahoda (1982) argued that one's status was often defined by one's job. This notion was supported by Donovan and Oddy (1982) when they found that older workers who became unemployed lost their work related identity, while school-leavers entering the workforce were faced with the prospect of establishing a work identity. Status has also been shown to be related to psychological wellbeing. Evans and Haworth (1991) found that status was significantly correlated with wellbeing independent of activity. Haworth and Patterson (1995) reported that status in leisure time had a strong relationship with psychological wellbeing. Creed and Machin (2001) found that status was the lone latent benefit that was a significant individual predictor of wellbeing in their sample of 161 unemployed individuals.

The second influential model proposed to account for the deterioration in wellbeing as a result of unemployment is the Agency Restriction Model (Fryer, 1986). Fryer (1995) considered individuals to be, "socially embedded agents who are actively striving for purposeful determination, attempting to make sense of, initiate, influence and cope with events in line with personal values, goals, expectations of the future in a context of cultural norm, traditions and past experience" (p. 270). He considered that the main negative consequence of unemployment was not the loss of the latent benefits as argued by Jahoda, but rather it was the loss of the manifest benefits (loss of income). Fryer (1995) considered that “...unemployment generally results in psychologically corrosive experienced poverty" (p. 270), and it was this experience of poverty 
that severed the individual from a meaningful future and led to a reduction in psychological health. Fryer also acknowledged the role that the latent benefits of employment played in mental health (Fryer \& Payne, 1984), but considered these insufficient to fully explain the deterioration in wellbeing experienced by the unemployed.

Fryer and McKenna (1987) have provided support for the Agency Restriction Model. These authors compared two groups of unemployed men who were laid off from their factory jobs. One group had been made temporarily redundant, while the other had been laid off indefinitely. These authors found, contrary to what would be predicted by the Deprivation Model, that both groups were not equally deprived of the latent benefits, and were not equally psychological distressed. Those who were only temporarily laid off had organized active and productive lives and appeared to be psychologically healthy, which was not the case for the indefinitely retrenched group. Fryer and McKenna concluded that the temporarily laid off men, who were more optimistic about the future, were able to organize and obtain the latent benefits outside of the work environment, and would eventually return to work for the manifest, rather than the latent benefits.

A number of other studies have provided evidence that financial hardship plays a substantial role in the lives of unemployed people. Firstly, Jackson (1999) found that unemployed individuals reported more financial stress than employed or student samples, and Kokko and Pulkkinen (1997) in a study comparing unemployed to employed, found that the unemployed experienced more financial strain and were more distressed. Dew, Bromet and Penkower (1992) found an association between financial difficulties and depression in a sample of unemployed women, and a similar link has been reported for unemployed people in general (Vinokur, Price \& Caplan, 1991). Using a large-scale Irish national database, Whelan (1992) examined both subjective experiences of financial strain and objective material deprivation in a large cohort of unemployed individuals, and concluded that poverty, as construed by these two broad variables, 
played a substantial role in mediating the effects of unemployment for both the individual involved and the person's family.

The evidence here is firstly that unemployed people have less access to the latent benefits of employment, and that loss of these benefits is associated with lower levels of psychological wellbeing. Support for these assertions comes from studies that have examined the latent benefits in an aggregated manner, as well as when they have been examined individually. In relation to the relative importance of the individual latent benefits, Jahoda herself argued that time structure was the most important benefit. Several authors (Evans, 1986; Evans \& Haworth, 1991) have cited activity as the preeminent benefit, while Creed and Machin (2001) concluded that status was the single best latent benefit predictor of psychological wellbeing. The issue as to the relative importance of the latent benefits is clearly unresolved. Secondly, unemployed people have less access to the manifest benefits of employment, and the loss of these benefits has been shown to be associated with poorer psychological wellbeing. The research to date however has largely tested the two theories independently, and not examined the two approaches in concert. Jahoda (1982) clearly suggested that psychological distress was also associated with "an inadequate standard of living" (p. 28). Similarly, Fryer acknowledged the part played by the latent benefits of employment in the maintenance of wellbeing (Fryer \& Payne, 1984). There is a need to examine the impact of unemployment on wellbeing by testing the impact of both the latent and manifest benefits. Lastly, in relation to the latent benefits, no study has examined the relative importance of the five individual factors in relation to wellbeing. There is a need to examine the relative importance of loss of these benefits on the psychological wellbeing of unemployed people.

The present study will examine the relative contributions of the latent and manifest benefits of employment in predicting psychological wellbeing in a sample of unemployed adults. Firstly, in line with Jahoda's theory it is predicted that there will be significant associations between the 
latent benefits of employment and wellbeing. Secondly, consistent with Fryer's theory it is predicted that there will be significant associations between the manifest benefits of employment and wellbeing. Thirdly, consistent with acknowledgements from both theorists and the empirical evidence it is predicted that both the latent and manifest benefits of employment will be significant predictors of wellbeing. Fourthly, from the empirical evidence of the pervasive impact of poverty it is predicted that the manifest benefit will account for the largest proportion of the variance in wellbeing. Lastly, in line with the theorising of Jahoda and the empirical evidence of the relative importance of the latent benefits it is expected that time structure, activity and status will be the most influential latent benefits in predicting wellbeing in the unemployed sample.

\section{Method}

\section{Participants}

Participants were 248 unemployed men and women who were recruited from the national employment agency in southeastern Queensland, Australia, where all were registered and seeking employment. The sample was made up of 133 (54\%) males and $115(46 \%)$ females, whose mean age was 28.02 years $(S D=9.69$, Range $=16-65)$. Participants had been unemployed for 11.41 months on average $(S D=16.90$, Range $=<1$ month -108 months $)$.

\section{Materials}

Psychological Wellbeing. The 12-item version of the General Health Questionnaire (GHQ) (Goldberg, 1972) was used to provide a global measure of psychological distress. The 12-item version has been recommended by Banks et al., (1980) for use in occupational studies, and has been used extensively by researchers in this area (e.g., Bond \& Feather, 1988; Warr, 1987). Participants were asked to indicate how they felt recently on a range of variables, including cognitive processing, self-esteem, anxiety and depression (e.g., "Have you recently been able to 
concentrate on whatever you're doing?", and "Have you recently been feeling unhappy and depressed?"). Responses were scored on a four-point scale from zero to three using anchors such as "better than usual/same as usual/less than usual/much more than usual". Scores were totaled to produce global ratings with a possible range of 0-36. Higher scores indicated more psychological distress. Goldberg and Williams (1988) reported a mean internal reliability coefficient of 0.85 for the scale. In the present study, the internal reliability coefficient was 0.91 .

Financial Strain. The manifest benefit of employment was operationalised as Financial Strain. This was measured using a four-item scale that has been utilised widely for this purpose with unemployed people (e.g., Ullah, 1990; Warr \& Jackson, 1987). The four items were: (1) "Do you have serious financial worries?", (2) "Are you often not able to do the things you like to do because of shortages of money?", (3) "Are you often not able to do the things you need to do because of shortages of money?", and (4) "Are you often not able to manage on the money you have?". Respondents were asked to indicate the extent to which they experienced financial difficulties on five-point scale using endpoints of "never" to "all the time". This gave a possible range of 4-20, with higher scores indicating greater levels of financial strain. Ullah reported an internal reliability coefficient of 0.77 with an unemployed sample. In the present study, the internal reliability coefficient was 0.91 .

Time Structure. The latent benefit of Time Structure was measured by a five-item scale developed by Rowley \& Feather (1987). The five items were: (1) “Once I've started an activity I persist until I've completed it", (2) "I plan my activities so that they fall into a particular pattern during the day", (3) "I get bored with my day-to-day activities", (4) "My main interests/activities fulfil some purpose in my life", and (5) "I feel that I can't be bothered doing anything at all, even those activities which used to interest me". Respondents were asked to indicate the extent to which they agreed/disagreed with these items on a seven-point scale using endpoints of "strongly agree" and "strongly disagree". This gave a possible range of responses of 5-35, with higher 
scores indicating more time structure. Rowley and Feather reported an internal reliability coefficient of 0.65 with a sample of unemployed males. In the present study, the internal reliability coefficient for the scale was 0.66 .

Activity. The latent benefit of Activity was measured using a three three-item sub-scale drawn from the Access to Categories of Experience (ACE) scale (Evans, 1986). The three items were: (1) "My time is filled with things to do", (2) The things I have to do keep me busy most of the day", and (3) "Much of the day I've got things to do at regular times". Respondents were asked to indicate the extent to which they agreed/disagreed with these items on a seven-point scale using endpoints of "strongly agree" and "strongly disagree". This gave a possible range of 3-21, with higher scores indicating more activity. Evans and Banks (1992) reported satisfactory internal reliability data for the sub-scales and total ACE scale with a large sample of unemployed people. For the present study, the internal reliability coefficient was 0.83 .

Social Contact. The latent benefit of Social Contact was also measured using a three-item subscale from the Access to Categories of Experience scale. The three items for this sub-scale were: (1) "Most days I meet quite a range of people", (2) "I don't get to meet many people regularly", and (3) "I see a lot of my friends or workmates". Respondents were asked to indicate the extent to which they agreed/disagreed with these items on a seven-point scale using endpoints of "strongly agree" and "strongly disagree". This gave a possible range of 3-21, with higher scores indicating more social contact. The internal reliability coefficient for this sub-scale in the present study was 0.74 .

Status. The latent benefit of Status was also measured using a three-item sub-scale from the Access to Categories of Experience scale. The three items for the Status sub-scale were: (1) "Sometimes I feel like I am on the scrapheap", (2) "I sometimes think that people are looking down on me', and (3) "Society generally respects people like me". Respondents were asked to indicate the extent to which they agreed/disagreed with these items on a seven-point scale using 
endpoints of "strongly agree" and "strongly disagree". This gave a possible range of 3-21, with higher scores indicating higher status. The internal reliability coefficient for this sub-scale in the present study was 0.60 .

Collective Purpose. The latent benefit of Collective Purpose was measured using a three-item scale drawn from a scale developed by Congdon (1990). The three items for this scale were: (1) "I am able to count on my friends to let me know when I am getting out of line", (2) If I need some good advice I can get it from my friends", and (3) "I am able to work with other people on goals I want to achieve and to make progress on my goals". Respondents were asked to indicate how much they agreed/disagreed with these items on a seven-point scale using endpoints of "strongly disagree" and "strongly agree". This gave a possible range of 3-21, with higher scores indicating more collective purpose. Congdon found satisfactory internal reliability for this scale on a sample of unemployed people. An internal reliability coefficient of 0.75 was calculated for the present study.

\section{Procedure}

A cross-sectional survey design was utilised. The survey consisted of scales to measure the one manifest and five latent benefits of employment, psychological wellbeing, and questions regarding age, gender and length of unemployment. Unemployed people who were using the national employment agency across three sites were approached by the researchers to participate in the study.

\section{Results}

Summary data for all dependent variables, age and length of unemployment are reported in

Table 1. In relation to gender, a series of independent sample t-tests indicated no differences 
between males and females on any of the dependent variables of Psychological Distress (GHQ12), Financial Strain, Time Structure, Activity, Social Contact, Collective Purpose or Status. No gender differences were found for Length of Unemployment. In this sample, males were significantly older than females, $t(246)=2.24, \mathrm{p}<.05$. Moderate to strong correlations (all $\geq .33$ ) were found between GHQ-12 and the latent (Time Structure, Activity, Social Contact, Collective Purpose and Status) and manifest (Financial Strain) benefits of employment. Similarly, there were moderate to strong correlations among the latent and manifest benefits (all $\geq .26$ ). No meaningful relationships (i.e., $\geq .33$; Tabachnick \& Fidell, 1996) were found for age or length of unemployment. The variables of age, gender and length of unemployment were not considered in further analyses. 
Table 1

Means, standard deviations and bivariate correlations for GHQ-12, Financial Strain, Time Structure, Activity, Social Contact, Collective Purpose, Status, Age, and Length of Unemployment for all participants; $N=248$.

\begin{tabular}{|c|c|c|c|c|c|c|c|c|c|c|c|}
\hline Variable & $\underline{\mathrm{M}}$ & $\underline{\mathrm{SD}}$ & 1 & 2 & 3 & 4 & 5 & 6 & 7 & 8 & 9 \\
\hline 1. GHQ-12 & 14.29 & 7.69 & - & $.61 * * *$ & $-.47 * * *$ & $-.33 * * *$ & $-.34 * * *$ & $-.39 * * *$ & $-.56 * * *$ & .05 & .00 \\
\hline 2. Financial Strain & 12.45 & 4.38 & & - & $-.32 * * *$ & $-.26 * * *$ & $-.27 * * *$ & $-.33 * * *$ & $-.50 * * *$ & .08 & .02 \\
\hline 3. Time Structure & 25.46 & 5.34 & & & - & $.55 * * *$ & $.35 * * *$ & $.37 * * *$ & $.38 * * *$ & .11 & .07 \\
\hline 4. Activity & 15.14 & 4.51 & & & & - & $.35 * * *$ & $.29 * * *$ & $.32 * * *$ & .05 & .15 \\
\hline 5. Social Contact & 14.00 & 4.51 & & & & & - & $.32 * * *$ & $.36 * * *$ & $-.22 * *$ & -.03 \\
\hline 6. Collective Purpose & 16.05 & 4.18 & & & & & & - & $.28 * * *$ & -.09 & -.06 \\
\hline 7. Status & 11.93 & 4.31 & & & & & & & - & -.09 & -.06 \\
\hline 8. Age & 28.02 & 9.69 & & & & & & & & - & $.21 * *$ \\
\hline 9. Unemployment & 11.41 & 16.90 & & & & & & & & & - \\
\hline
\end{tabular}

Note: GHQ-12 = 12-item General Health Questionnaire; Financial Strain = four-item measure of financial strain; Time Structure = five-item measure of time structure; Activity = three-item measure of regular activity; Social Contact $=$ three-item measure of social contact; Collective Purpose $=$ three-item measure of collective purpose; Status $=$ three-item measure of status; Unemployment $=$ Length of unemployment in months; $* * \mathrm{p}<.01 ; * * * \mathrm{p}<.001$. 


\section{Predicting Wellbeing}

A standard multiple regression analysis was conducted to determine the relative contribution of the latent (Time Structure, Activity, Social Contact, Collective Purpose and Status) and manifest (Financial Strain) benefits of employment in predicting Psychological Wellbeing (GHQ12). The independent variables were Time Structure, Activity, Social Contact, Collective Purpose, Status and Financial Strain, and the dependent variable was Psychological Wellbeing (GHQ-12). Summary data for this analysis are reported in Table 2. The semi-partial regression coefficients for each predictor variable are also included in Table 2. A semi-partial regression coefficient is the contribution of an individual predictor variable to the dependent variable after the other predictor variables have been statistically controlled.

The results of this analysis show that together the variables account for a significant $52.10 \%$ of the variance in Psychological Wellbeing, $\underline{F}(6,241)=43.65, \underline{p}<.001$. Financial Strain was the most important predictor of wellbeing $(\underline{B}=.37)$ making a significant unique contribution of $16.81 \%, \underline{\mathrm{t}}(241)=7.00, \underline{\mathrm{p}}<.001$. Status was the second most important predictor $(\underline{B}=-.25)$ making a significant unique contribution of $7.84 \%, \underline{t}(241)=-4.49, \underline{p}<.001$. Time Structure was the third most important predictor in this sample $(\underline{B}=-.21)$ making a significant unique contribution of 5.30\%, $\underline{\mathrm{t}}(241)=-3.67, \underline{\mathrm{p}}<.001$. Lastly, Collective Purpose $(\underline{\mathbb{B}}=-.11)$ made a significant unique contribution of $1.96 \%, \underline{t}(241)=-2.20, \underline{p}<.05$. Predictor variables Activity and Social Contact, although contributing to the overall variance, were not significant individual predictors of Psychological Wellbeing. Thus, from this analysis it can be seen that the manifest and latent benefits of employment together were able to account for a significant proportion of the variance of Psychological Wellbeing in this sample of unemployed people. The manifest 
benefit of Financial Strain was the largest individual predictor of Psychological Wellbeing, followed in turn by the latent benefits of Status, Time Structure and Collective Purpose.

Table 2

Summary data for Standard Multiple Regression Analysis for Variables Predicting Psychological Wellbeing; $N=248$.

\begin{tabular}{lcccc} 
Variable & $\underline{\mathrm{B}}$ & $\underline{\mathrm{SE} \mathrm{B}}$ & $\underline{B}$ & Semi-partial \\
\hline Financial Strain & 0.65 & 0.09 & $0.37^{* * *}$ & .41 \\
Time Structure & -0.30 & 0.08 & $-0.21^{* * *}$ & -.23 \\
Activity & 0.02 & 0.09 & 0.01 & -.01 \\
Social Contact & -0.10 & 0.09 & -0.06 & -.07 \\
Collective Purpose & -0.20 & 0.09 & $-0.11^{*}$ & -.14 \\
Status & -0.44 & 0.10 & $-0.25^{* * *}$ & -.28 \\
& & & & \\
\hline
\end{tabular}

Note: $R^{2}=0.52 ;$ Adjusted $R^{2}=0.51 ; *=p<.05 ; * * *=p<.001$. Refer Table 1 for legend.

\section{Discussion}

The first implication from the study is that the latent (Latent Deprivation Model) and manifest benefits (Agency Restriction Model) of employment when taken together were able to predict a significant and meaningful $52 \%$ of the variance in psychological wellbeing in this sample of unemployed people. This confirms the usefulness of both approaches in explaining the negative psychological experiences associated with unemployment. Clearly, neither theory alone was sufficient to provide a full explanation of this psychological deterioration so widely reported, with both the latent and manifest benefits individually being able to make significant contributions to predicting psychological wellbeing. This means that any account of the experiences of unemployed people needs to consider the loss or absence of the latent benefits usually associated with employment as well as the loss of material income with its implications 
for financial distress and reduced capacity to be proactive and forward looking. Models that incorporate both latent and manifest benefit variables will provide a more complete explanation of psychological wellbeing in the unemployed than models that focus on one of these dimensions alone.

Psychological wellbeing was most strongly correlated with financial strain, and financial strain emerged as the most important predictor of wellbeing. The evidence here is that financial concern is the more important factor associated with psychological distress. This is inconsistent with the theorising of Jahoda who acknowledges but downplays the role that income plays in maintaining wellbeing. It is clear that the effect of financial impoverishment plays a key role in the reduction in psychological wellbeing.

Jahoda proposed that there were five latent benefits of employment. Despite her belief that time structure was the more important benefit, she also argued that the five benefits were relatively equal in terms of their positive contribution to psychological wellbeing. The evidence from this study does not support this assumption. While there were significant and meaningful ( $\geq$ .33) correlations between all latent benefits and psychological wellbeing, the strongest associations were between time structure and wellbeing and status and wellbeing. Further, status, time structure and collective purpose emerged as the only significant individual predictors of wellbeing. There is support here for conjecture that time structure and status are more important correlates of wellbeing than the other latent benefits. It may also be that a more parsimonious latent benefit model may be sufficient to explain wellbeing in unemployed people.

At a practical level, there are implications for the types of interventions that might be developed for unemployed people, where a goal is to improve their psychological functioning. Basic income level programs where all citizens are guaranteed a level of income by the State 
sufficient to provide for basic living expenses have been proposed and need to be further examined (Shortt, 1996). The evidence from this study is that such programs are likely to contribute to reductions in the psychological distress caused by unemployment although not eliminate it. Providing unemployed people with better financial management skills, e.g., related to budgeting, smarter purchasing and developing saving plans could be undertaken at the individual level. Individual interventions might also specifically target improving access to the latent benefits of time structure and status, identified in this study as the more important latent benefits. Examples here might be training in time planning and time management, and providing strategies for coping with the widespread negative community stereotypes.

Lastly, a number of issues arise in relation to future research in this area. One limitation of the present study was that the research was based on self-report survey data. Future studies should attempt to include data from multiple sources and be augmented with non-survey designs. Related to this issue is the need for more reliable assessment tools that better measure the latent benefits of employment. Even though the scales utilised in the study were drawn from the literature, and were considered adequate, they cannot be considered sufficient to cover the constructs proposed by Jahoda. Second, Fryer's Agency Restriction Model needs to be better operationalised. While Financial Strain clearly forms a key aspect of the agency explanation there are other aspects that need to be examined. More specifically, scales need to be developed that tap future orientation for unemployed people. With more sophisticated measurement tools it would then be possible to test more complex models related to the prediction of psychological wellbeing in unemployed people. This study demonstrated that Financial Strain had a clear direct effect on psychological wellbeing. However, it is quite possible that Financial Strain will also have indirect effects on wellbeing by influencing other variables in the model. There is some 
evidence for these indirect effects from the correlations between Financial Strain and the latent variables. For example here, it is possible that Financial Strain will effect an unemployed person's level of Activity because fewer resources are available to engage in such activities. In this way Financial Strain may influence wellbeing in a direct fashion as well as indirectly by reducing activity levels. It is also possible that there will be indirect effects among the latent variables, and future studies should attempt to test predictions here. For example, it is possible that having reduced status might also effect levels of activity. Examining effects in this way will lead to a clearer understanding of the influences on wellbeing for the unemployed. 


\section{References}

Banks, M. H., Clegg, C. W., Jackson, P. R., Kemp, N. J., Stafford, E. M., \& Wall, T. D. (1980). The use of the General Health Questionnaire as an indicator of mental health in occupational studies. Journal of Occupational Psychology, 53, 187-194.

Bolton, W., \& Oatley, K. (1987). A longitudinal study of social support and depression in unemployed men. Psychological Medicine, 17, 453-460.

Bond, M. J., \& Feather, N. T. (1988). Some correlates of structure and purpose in the use of time. Journal of Personality and Social Psychology, 55(2), 321-329.

Congdon, D. C. (1990). Gender, employment and psychosocial well-being. Journal of Sociology \& Social Welfare, 17(3), 101-121.

Creed, P. A. \& Machin, M. A. (2001). The relationship between mental health and access to the latent functions of employment for unemployed and underemployed individuals. Manuscript submitted for publication.

Dew, M. A., Bromet, E. J., \& Penkower, L. (1992). Mental health effects of job loss in women. Psychological Medicine, 22(3), 751-764.

Donovan, A., \& Oddy, M. (1982). Psychological aspects of unemployment: An investigation into the emotional and social adjustment of school leavers. Journal of Adolescence, 5, 15-30.

Evans, S. T., \& Banks, M. H. (1992). Latent functions of employment: Variations according to employment status and labour market. In C. H. A. Varhaar \& L. G. Jansma (Eds.). On the mysteries of unemployment (pp. 281-295). Dordrecht, Netherlands: Kluwer Academic.

Evans, S. T., \& Haworth, J. T. (1991). Variations in personal activity, access to categories of experience and psychological well-being in unemployed young adults. Leisure Studies, 10, 249264. 
Feather, N. T. \& O'Brien, G. E. (1986). A longitudinal study of the effects of employment and unemployment on school leavers. Journal of Occupational Psychology, 59, 121-144.

Fryer, D. (1986). Employment deprivation and personal agency during unemployment: A critical discussion of Jahoda's explanation of the psychological effects of unemployment. Social Behaviour, 1(1), 3-23.

Fryer, D. (1995). Labour market disadvantage, deprivation and mental health benefit agency. The Psychologist, June, 265-272.

Fryer, D., \& McKenna, S. P. (1987). The laying off of hands: Unemployment and the experience of time. In S. Fineman (Ed.). Unemployment: Personal and social consequences (pp. 47-73). London: Tavistock.

Fryer, D., \& Payne, R. (1984). Proactive behaviour in unemployment: Findings and implications. Leisure Studies, 3(3), 273-295.

Goldberg, D. P. (1972). The Detection of Psychiatric Illness by Questionnaire. London: Oxford University Press.

Goldberg, D. P., \& Williams, P. (1988). A Users Guide to the General Health Questionnaire. Berkshire: NFER-NELSON.

Hammer, T. (1993). Unemployment and mental health among young people. A longitudinal study. Journal of Adolescence, 16, 407-420.

Haworth, J. T. (1997). Work, leisure and well-being. London: Routledge.

Haworth, J. T., \& Ducker, J. (1991). Psychological wellbeing and access to categories of experience in unemployed young adults. Leisure Studies, 10, 265-274.

Haworth, J. T., \& Paterson, F. (1995). Access to categories of experience and mental health in a sample of managers. Journal of Applied Social Psychology, 25(8), 712-724. 
Henwood, F. \& Miles, I. (1987). The experience of unemployment and the sexual division of labour. In D. Fryer \& P. Ullah (Eds.). Unemployed people (pp. 94-110). Milton Keynes: Open University Press.

Hepworth, S. J. (1980). Moderating factors of the psychological impact of unemployment. Journal of Occupational Psychology, 53, 139-145.

Jackson, T. (1999). Differences in psychosocial experiences of employed, unemployed, and student samples of young adults. Journal of Psychology, 133(1), 49-60.

Jahoda, M. (1982). Employment and Unemployment: A Social-psychological Analysis. London: Cambridge University Press.

Jahoda, M. (1984). Social institutions and human needs: A comment on Fryer and Payne. Leisure Studies, 3, 297-299.

Kilpatrick, R., \& Trew, K. (1985). Life styles and psychological wellbeing among unemployed men in Northern Ireland. Journal of Occupational Psychology, 58, 207-216.

Kokko, K., \& Pulkkinen, L. (1997). Economical and psychological well-being of the unemployed. Psykologia, 32, 349-359.

Miles, I. (1983). Adaptation to unemployment. Science Policy Research Unit. Brighton: University of Sussex.

Miles, I. \& Howard, J. (1984). A study of youth employment and unemployment. Science Policy Research Unit. Brighton: University of Sussex.

Muller, J., Hicks, R., \& Winocur, S. (1993). The effects of employment and unemployment on psychological well-being in Australian clerical workers: Gender differences. Australian Journal of Psychology. 45(3): 103-108. 
Murphy, G. C. \& Athanasou, J. (1999). The effect of unemployment on mental health. Journal of Occupational and Organizational Psychology, 72, 83-99.

Rowley, K. M., \& Feather, N. T. (1987). The impact of unemployment in relation to age and length of unemployment. Journal of Occupational Psychology, 60(4), 323-332.

Shortt, S. E. D. (1996). Is unemployment pathogenic? A review of current concepts with lessons for policy planners. International Journal of Health Services, 26, 569-589.

Tabachnik, B. G, \& Fidell, L. S. (1996). Using Multivariate Statistics. New York: HarperCollins College Publishers.

Ullah, P. (1990). The association between income, financial strain and psychological wellbeing among unemployed youths. Journal of Occupational Psychology, 63, 317-330.

Underlid, K. (1996). Activity during unemployment and mental health. Scandinavian Journal of Psychology, 37(3), 269-281.

Vinokur, A. D., Price, R. H., \& Caplan, R. D. (1991). From field experiments to program implementation. American Journal of Community Psychology, 19(4), 543-562.

Wanberg, C. R., Griffiths, R. F., \& Gavin, M. R. (1997). Time structure and unemployment: A longitudinal investigation. Journal of Occupational and Organizational Psychology, 70, 75-95.

Warr, P. B. (1987). Work, unemployment and mental health. Oxford: Oxford University Press.

Warr, P. B., \& Jackson, P. R. (1987). Adapting to the unemployed role: A longitudinal investigation. Social Science and Medicine, 25, 1219-1224.

Whelan, C. T. (1992). The role of income, life style deprivation and financial strain in mediating the impact of unemployment on psychological distress: Evidence from the Republic of Ireland. Journal of Occupational and Organizational Psychology, 65, 331-344. 
Winefield, A. H. (1995). Unemployment: Its psychological costs. In C. L. Cooper \& I. T. Robertson (Eds.). International Review of Industrial and Organizational Psychology. Chichester: Wiley.

Winefield, A. H., Tiggemann, M., \& Winefield, H. R. (1992). Spare time use and psychological well-being in employed and unemployed young people. Journal of Occupational and Organizational Psychology, 65, 307-313. 